\title{
Para-Haptics. A Touch of Marble
}

Among other things that make my day interesting, I am teaching a course titled Representation of movement in visual arts. It is an opportunity to question in an applied manner what role the senses play in art history. It is a haunting question for the lecturer who must harness the attention of his students in a journey through millennia of forms, which seem to rapidly lose any relevance in our daily experience and practice of culture. The course entails a mind game: my students' main subject is video art and computer imaging (both practice and theory). Since I am a practitioner in that field, it might seem logical that the 'movement' I will try to analyse pertains to contemporary art production. In actuality, our encounters are a wandering-through of moments in the history of forms from early Antiquity to the $20^{\text {th }}$ century, moments chosen for their relevance in a process of emotion creation: moving verbally through art (history) in search of what moves our brains into generating empathy (with art).

I am not looking for knowledge dissemination in those encounters: neither method sharing nor the establishment of a certain order of priorities in the approach of the fuzzy field of visual arts. I am interested in the slim chance of an awakening of awareness to the inner processes of the individual in (inter-mediated) contact with manifest objects. The intermediation through surrogate visuals (reproductions of various sorts) should be a hindrance and a complication. But it has not been, as what stays central to the approach is precisely the way in which the conglomeration of senses is activated by the contact with the image, or any image eventually.

What is essential here is thus another type of 'movement' - the circuit of information that goes from the eye, to the brain, to the skin, to the palm of the hand, to the brain again and, if all goes well, from there to a diffuse zone situated under the solar plexus, identified in Hinduism, Buddhism and Jainism as one of the chakras, and then back again to the brain and so on and so forth. Chakra comes from the Sanskrit word अनाहत which means, among other things, circle or wheel. It implies the process of return, of cyclic connection between different interdependent points, which is very much what I am trying to illustrate for my students with the derivative term 'Para-Haptics'.

The term 'haptics' first caught my attention at the end of the 1990s, when I was working on the possibility of unconventional physical interfaces adapted to navigate immersive $3 \mathrm{D}$ environments. It was my ambition to go beyond the responsive environments in Jeffrey Shaw's Legible City $^{1}$ (an interface bicycle), or my own Happy Doomsday! (a press-
1 The Legible City is an interactive art installation created in 1989, Nagoya, Japan. https://www. jeffreyshawcompendium.com/ portfolio/legible-city/.

2 Happy Doomsday! (1998-1999) was developed during an artist-inresidency project at $\mathrm{V}_{2}$. It created an apocalytic environment, using conventions of computer games . http://va.nl/archive/works/happydoomsday. 
chest fitness machine interface), into a zone where tactility would be a gateway to enhanced sensorial experience. As the domain of haptics research is already embedded in the industrial environment, I did not feel that anything new could come from there for the visual arts. Recent history proves me right-haptics is a common feature nowadays: we carry it in our pockets, in the smart phone.

Still, the concept remains central to my understanding of how our senses work, and it plays an essential role in relation to the visual, due to a characteristic that I describe as 'stealthness'. If the assumption of the haptics circuit sketched above is verified, it is a surreptitious, furtive and unobtrusive process. Using the smart phone as an example at hand (literally), we can better understand how the haptic relation enters the domain of daily routines to the point that it is no longer noticeable as an agent of sensual perception. However, we can try to limit this by embarking in an act of techno-critique: by recuperating the selfawareness of our relationship with the haptic processes, we interrupt the occultation ('stealthness') induced by the newest technologies in our relationship to the world of senses.

The concept of haptics entered modern language through the contribution of a fascinating German thinker, Max Dessoir (18671947). It is difficult to describe Dessoir's practice in just one sentence. As a student of philosophy and medicine, he practised psychology, in which he developed a theory about double personality that manifests in dreams and hypnosis. A deceptive area of his work involves magic and the paranormal (medium communication, poltergeist, etc.), of which he was a sceptical researcher. This last thread could indicate that Dessoir was a unconventional reader of phenomena, one who aspired to harness the unknown and the unfathomable with the instruments of practical science.

Dessoir was a man of his time not only because he could not ignore the strange but powerful combination of empiric research and fascination with the occult that defines the spirit of la Belle Époque (Beautiful Era) of that time; but also because he fought for the establishment of art history as an autonomous discipline. By the end of the $19^{\text {th }}$ century, Immanuel Kant's aesthetic view of the world, as formulated in his Critique of the Power of Judgment (Kritik der Urteilskraft, 1790), was so predominant in the thinking about art that it inevitably came into question. A plurality of disciplines started to peel at the onion of this complex subject - psychology, ethnology, archaeology, etc. Dessoir is credited with combining the top-down perspective of general aesthetics with the bottom-up approach of empirical exploration. His curious mind, which roamed from physiology to psychology to the visual arts, helped Dessoir bring together perception and art in his publication Aesthetics and Theory of Art (Ästhetik und allgemeine Kunstwissenschaft, 1906) and, in so doing, opened the gates for what came after: a continuous oscillation between representation and symbolism in the writing of art history.

Haptics acquires a central position in the context sketched above, as it expresses not only the perceptive dimension of our relation to the objective world, but also opens new possibilities for the understanding of the phenomenological processes that define this relation. A proponent of art as the process of creating forms, Dessoir was a psychologist who was praised by Sigmund Freud in his Three Essays on the Theory of Sexuality (Drei Abhandlungen zur Sexualtheorie, 1905) as well as a 
source of inspiration for The Double (Der Döppelganger, 1971) by Otto Rank. When Dessoir developed the term haptics as a necessary addition to the terms optics and acoustics in academic research, he was probably not only motivated by his practice as a psychologist, where the sense of touch is relevant in both pathology and diagnosis (autism, hysteria, etc.), but was also prompted by his attraction to the uncharted-the complex gratification experienced in relation to art. ${ }^{3}$

Interestingly, around 1889, some three years before denominating haptics, Dessoir had already begun exercising his sense of linguistic invention with the term 'parapsychology'. In his words, parapsychology would present the advantage of defining "a fringe area between the average and the pathological states," while remaining cautious about the limited practical value of such neologisms. It is this ambiguity between concept and usefulness, between language and perception, that gives me reason for considering Dessoir's 'haptics' as more than a concept derived for practical necessity. When talking or writing about 'para'-haptics, I do so with a focus on this method of enriching by undermining, a method that characterised Dessoir's own way of thinking. What interests me in his definition of haptics is not the exacerbation of the sense of touch, but the role of the visual in multisensorial perception of cultural products.

It is useful to look at the etymology of the word 'haptics'. There are three

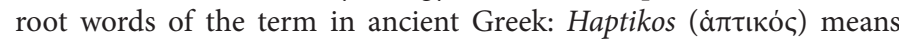
"pertaining to the sense of touch"; haptesthai (ä $\tau \tau \varepsilon \sigma \theta a \mathrm{l})$ means "to contact" or "to touch"; and haptein (ä $\pi \tau \varepsilon เ v)$, means "to fasten", or "to bring two things together." While the first two root words point, rather straightforwardly, to the sense of touch, haptein is more ambiguous and general, and implies a process. It is more about communication than direct action. It induces the idea of a binding relation among all the senses, of which the most elusive, least connected sense to the conscious brain is touch. By bringing touch into the realm of visual perception, Dessoir opened a gateway to understanding cultural production that goes beyond art itself.

Let us turn our attention to Max Dessoir's more famous contemporary, Alois Riegl. In his work Late Roman Art Industry (Spätrömische Kunstindustrie, 1901), this brilliant member of the Vienna School of Art History plays at length with the term of haptics, which, in his text, becomes a concept pertaining to the history of various methods of generating art. For Riegl, haptic perception and optic perception are two phases in the making and perceiving of art. He unified those two steps under the concept Kunstwollen (a more or less autonomous drive of a community towards a certain stylistic development, independent of technical concerns or cultural imitation). Riegl also analysed this concept in relation to Nature, and identified three stages of perception:

1. The haptic: contemplation of an object at close range, with a total rejection of the natural environment, of which the art object itself purposefully defies attention. A possible example, according to Riegl, is Egyptian reliefs. Their flat and subtle surfaces require arm's length contemplation.

2. The intermediary: contemplation at medium range, with the object sharing some optical space with the natural environment. An example could be Classical Greek reliefs and architectural decorations. Haptics still plays a role in this stage of perception.
${ }^{3}$ Haptics appears in his book Ueber den Hautsinn (1892), which can be translated, approximately, to On the Sense Exercised through the Skin. 
3. The optic: contemplation of a broad category of objects whose visual powers are intended to be shared with the natural environment, but which also simultaneously resist it; by extension, these objects require contemplation from a generous distance. Riegl considered Late Roman art a good example of such objects.

What fascinates me here is not so much the academic search for perception-system, characteristic to Riegl's writings, but rather the symbolic value of the 'haptic-optic', 'close-distant' coupling of terms. One should not be fooled by the technicalities described above, as it all boils down to participation in the complex act of seeing, which involves all the senses, in different proportions. The cultural ' $\mathrm{I}$ '-carrier of various experiences and a moving psychological profile-comes into contact with visual phenomena through a combination of sensory channels, as well as direct and previous experiences mediated through memories. For me, the Parthenon Frieze is filled with a complex architecture of sounds that is generated by a cavalcade through the narrow, cobbled streets of an old city: horses snort and whinny; men shout and laugh; hooves slip on larger stones or hit the flat, hard surfaces; the soft swish of the tunics' fabric moved by the wind, etc. However, this is my experience, which cannot - and should not—be multiplied.

The haptic experience is not merely a practical response and a sensorial consequence of stealth remote control systems (as the touchless haptictechnology proposes nowadays in various interfacing devices) which are feeding our lust for domination over the physical environment. It is a complex way of bringing together the visual, tactile, emotional and cultural in a fluid process without a specific goal, and therefore without a determined timeline, that goes from cause to effect, from motivation to action to result. The stealthness I mentioned above is unawareness about the sophistication of our own experiences in the domain of the visual. This sophistication is not necessarily ours, as individuals, but it pertains to the complexity of the domains involved. Thus, it is necessary to bring the term haptics into the realm of para-haptics, in order to broaden its scope and give the concept the capacity to cover "a fringe area between the average and the pathological states"- to apply Dessoir's way of explaining the notion of para-psychology.

In the Craiova Art Museum, among other masterpieces by Constantin Brâncuși, there is one that I consider among his most intriguing work. It is called Torso, an inappropriate way of titling-from misplaced prudery, I would say-since the sculpture clearly represents a fragment of the lower body of a female nude - her thigh. The sculpture cannot be categorised as being inspired by a grown female model, as it does not have the maturity of shapes; the dimensions of the thigh are indicative of the body of a little girl, but the soft roundness of its form is still suggestive of sexuality, contradicting the evidentiary information of the body's age as proposed by a measurement-analysis data. The anatomic treatment is ambiguous but the overall sculpture is precise in the sense of its finish-the minute definition of the surfaces and its texture. The marble is polished to a tender surface that captures light without sending it away: there is no reflection, or barely. There is no transparency either, although from certain angles or, in strong light, the stone hints at translucid, to a total complicity with the sun, to abandonment. Apart from the anatomical one, there is a second ambiguity-between the shape and the light surrounding it. Then, there is a third and last ambiguity, which is even subtler-between subject and scale. 

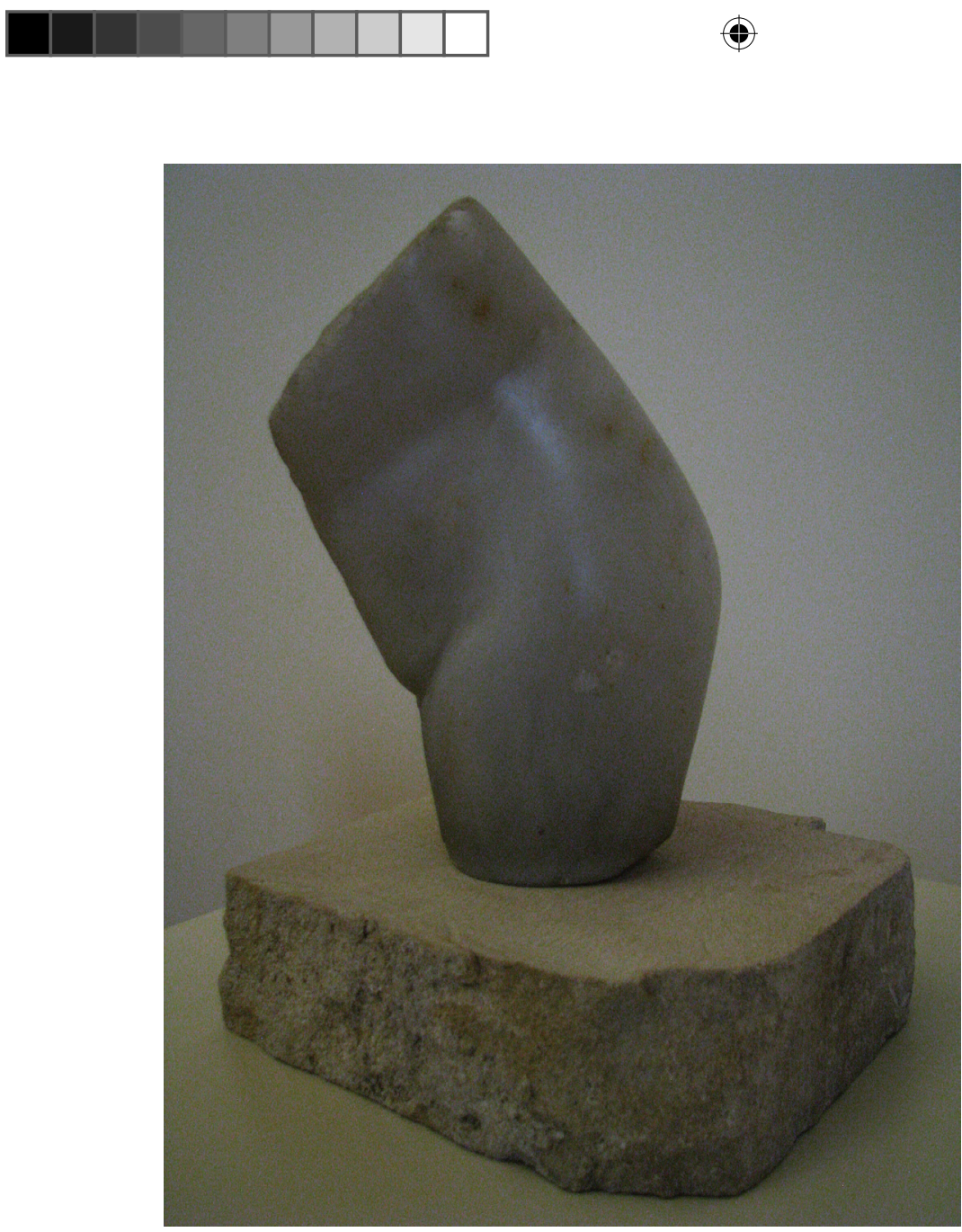

Constantin Brâncuși, Torso, 1912, Art Museum, Craiova Photo: Călin Dan

While contemplating the stone from different angles, the viewer acquires contradictory information. The front left side is defined by pudicity, due to the defensive bending of the nude, as if it is trying to hide its pubic area. From the back left side, the same act of bending acquires sexual notes, a promise of submission. It suggests that the viewer is looking at a mature body, rendered in sub-natural dimensions, like in so many late Classical Greek frieze sculptures (such as the Bassae Frieze of the Temple of Apollo Epicurius, the Mausoleum from Halicarnassus, and the Nereid Monument at Xanthos). These ambiguities evoke the intermediary contemplation method detailed by Riegl-characterised, according to him, as a combination of haptic and optic.

The contemplation of ambiguities is foreplay and prepares the viewer for the full-blown contact with the roundness of the stone, or better yet, the absence of it. When the viewer takes a step back from the sculpture, the thigh appears as an anatomic fragment partially extracted from a small block of marble. The body is minutely described in the front; it is brutally cut, asymmetrically, along the vertical axis, which sections the softness of the abdomen and pubis, and also leaves a damaged (unfinished) portion of the inner left thigh. The cut is asymmetrical in depth as well. From the back, where the erotic innuendo lies, the body is not sectioned, but is held prisoner with its right half in the grained, rough, dirty part of the untouched marble block. 


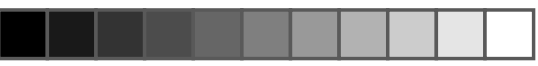

$\oplus$
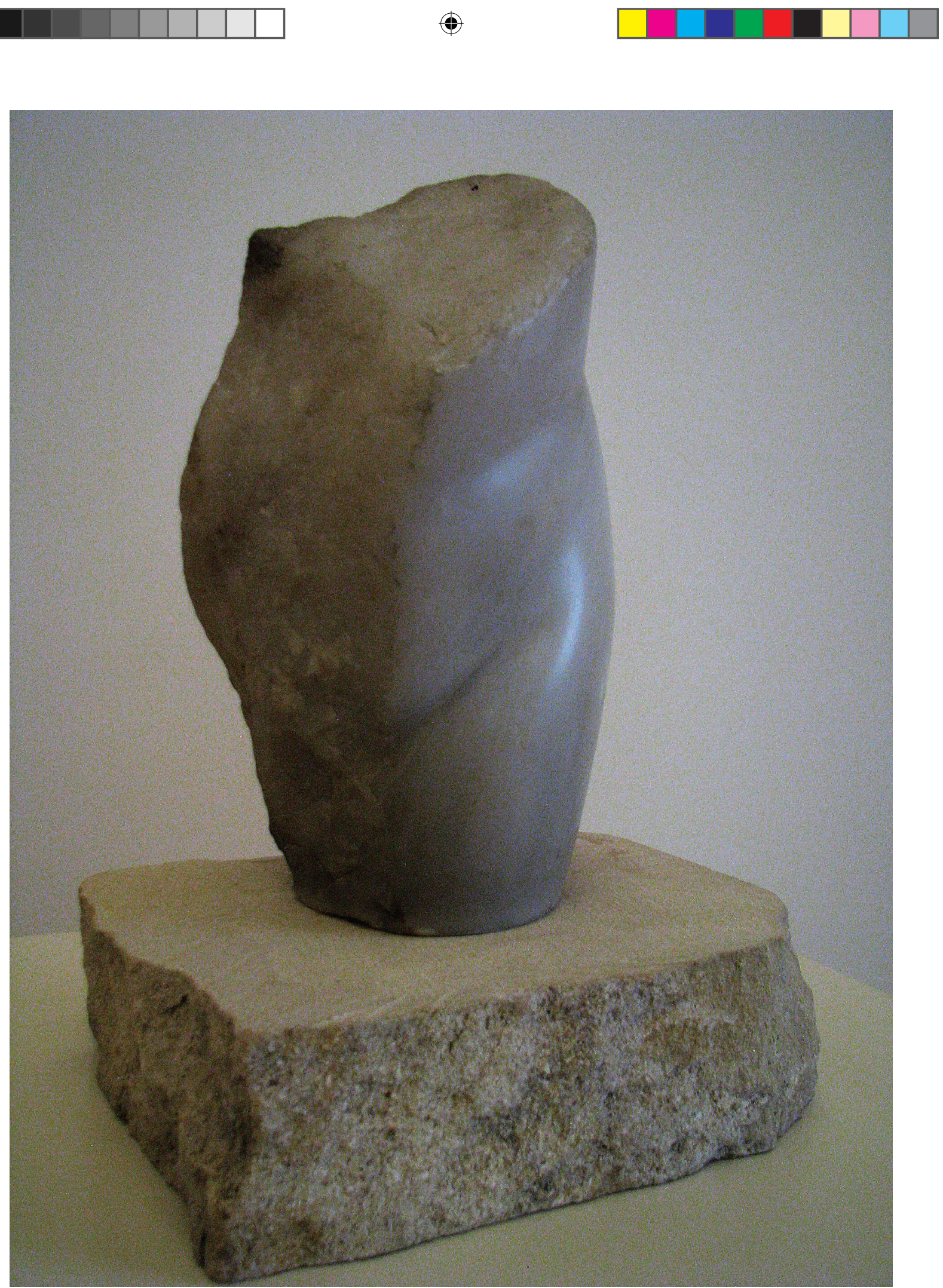

Constantin Brâncuși, Torso, 1912, Art Museum, Craiova. Photo: Călin Dan 

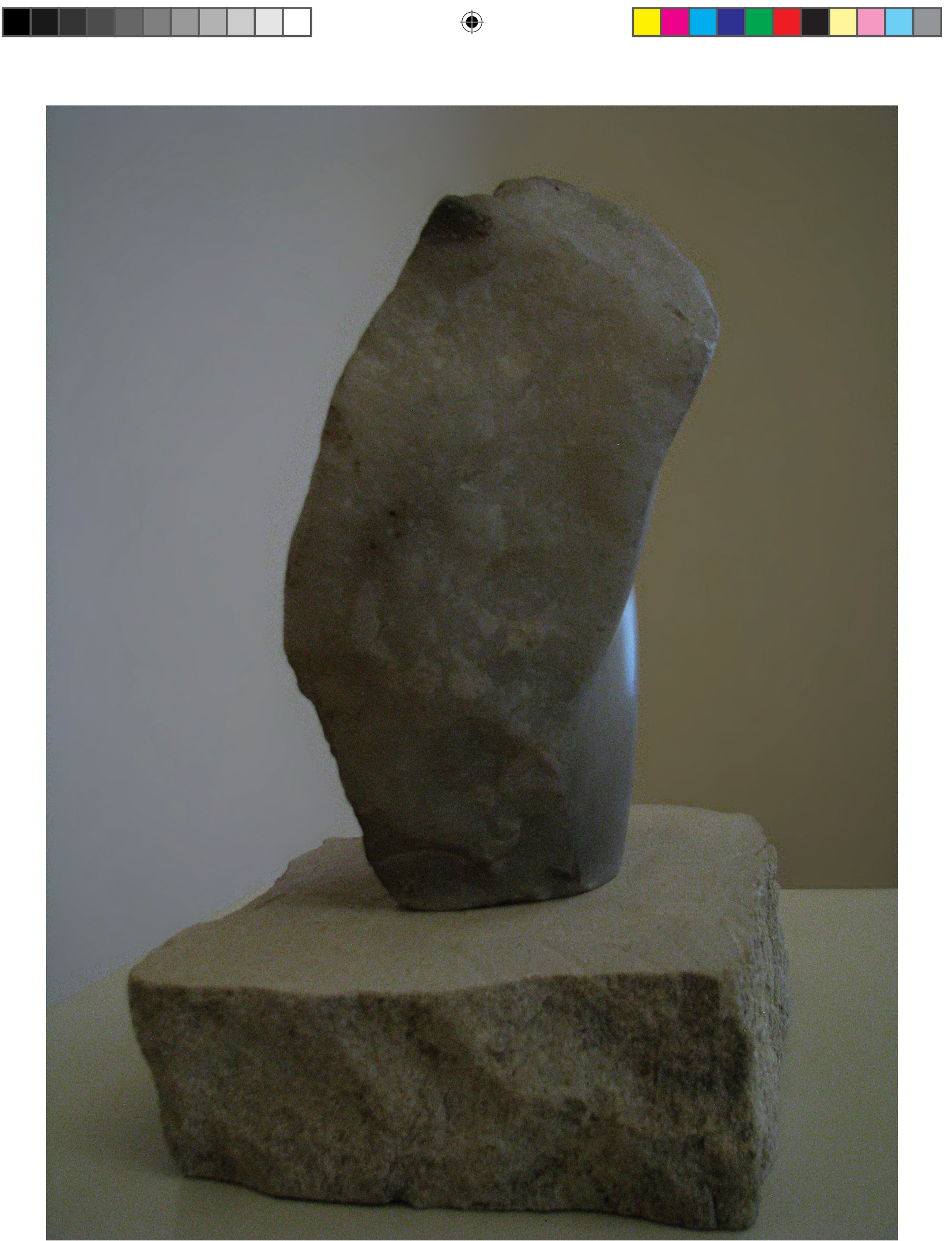

$\oplus$

Constantin Brâncusi, Torso, 1912, Art Museum, Craiova. Photo: Călin Dan 


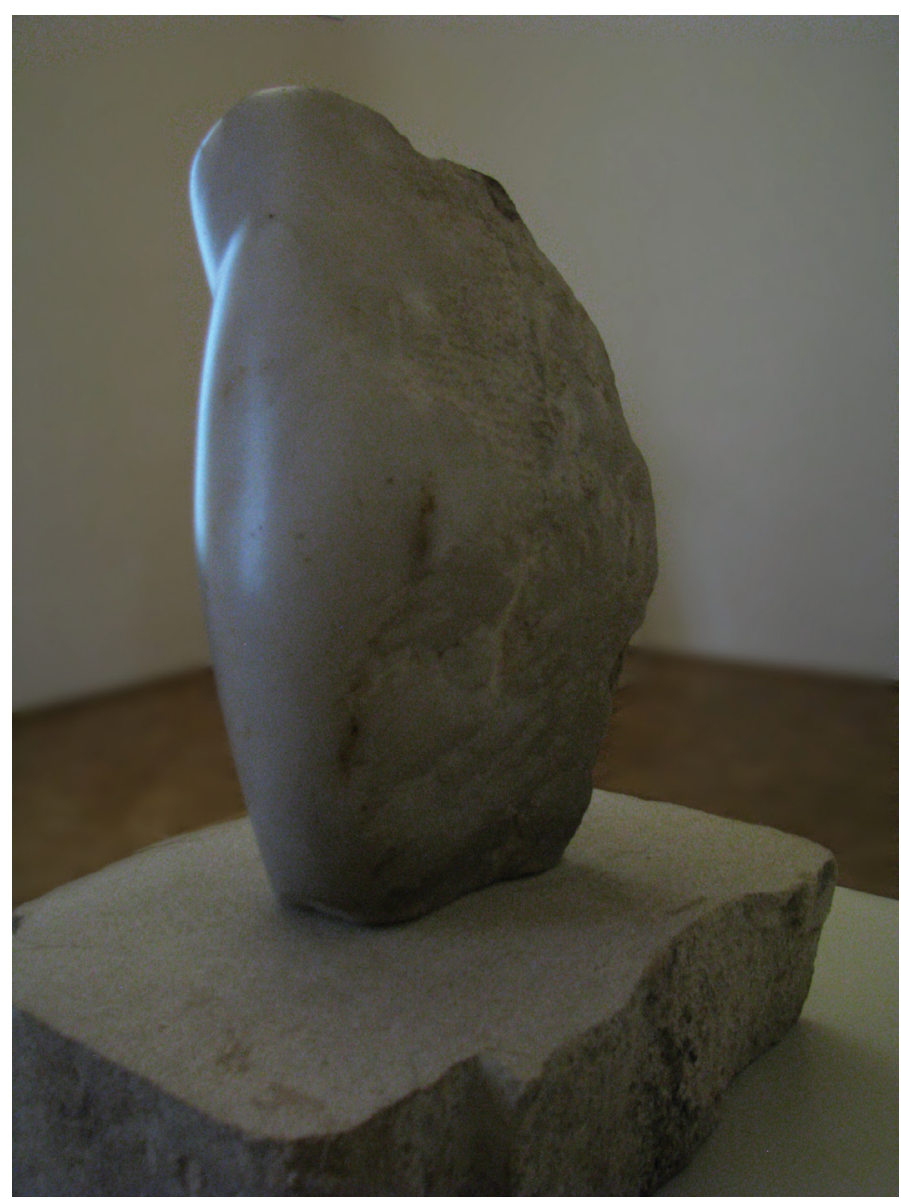

Constantin Brâncuși, Torso, 1912, Art Museum, Craiova. Photo: Călin Dan

Eventually, the viewer is overcome by the evidence that Brâncuși's work (which, to my mind, should have been titled Thigh) is a condensed look at the history of the act of sculpting-from the relation between carver and quarry, to the collaboration between sculptor and model, to the dialogue between sculpture and architecture. In 1912, a mature Brâncuși demonstrated mastery but also empathy with 2.5 millennia of art history. He achieved this with a small piece of marble, that bends and vibrates in soft light. Needless to say, the skin (this much ignored organ that enables haptics) is central to the composition of the thigh. The broken skin, cut violently along the lines of the elemental marble, is a suggestive image for ending this journey through the maze perception defined, more than a hundred years ago by Max Dessoir, as haptics. 


\section{References}

Dessoir, Max. Ueber den Hautsinn (On the Sense Exercised through the Skin). Harvard University, 1892. Reprint.

Dessoir, Max. Ästhetik und allgemeine Kunstwissenschaft (Aesthetics and Theory of Art), Stuttgart: F. Enke, 1906. Print.

Freud, Sigmund. Drei Abhandlungen zur Sexualtheorie (Three Essays on the Theory of Sexuality). Leipzig und Wien: Franz Deuticke, 1905.

Kant, Immanuel. Kritik der Urteilskraft (Critique of the Power of Judgment) 1790. Print.

Rank, Otto. The Double (Der Döppelganger). Transl. Harry Tucker Jr, Chapel Hill : University of North Carolina Press, 1971.

Riegl, Alois. Late Roman Art Industry (Spätrömische Kunstindustrie). Vienna, 1901.

Shaw, Jeffrey. https://www.jeffreyshawcompendium.com/portfolio/ legible-city/. Accessed 18 June 2018.

V2ᄀ__Lab for the unstable Media. http://va.nl/archive/works/happydoomsday. Accessed 18 June 2018. 